\title{
Interictal acute psychoses in temporal lobe epilepsy during withdrawal of anticonvulsant therapy
}

\author{
V.A.S I R O N I, A. F R A N Z I N I, L.R A V A G N A T I, \\ A N D F. MAROSSERO \\ From the Institute of Neurosurgery, School of Medicine, University of Milan, Italy
}

SUMMARY Acute interictal psychotic attacks during withdrawal of medication are described in two patients with temporal lobe epilepsy submitted to depth EEG study with a view to surgical treatment. The patients were on chronic treatment with clonazepam associated in one with phenobarbitone and in the other with phenobarbitone plus carbamazepine. Our observations suggest that the acute withdrawal of clonazepam, the plasma levels of which were monitored, may play a part in producing psychotic attacks characterised by dysphoric manifestations, irritability, aggressiveness, anxiety, and hallucinations. These symptoms could be interpreted as a withdrawal syndrome.

A relatively high incidence of psychiatric disorders has been found in patients suffering from temporal lobe epilepsy (Bruens, 1975; Pond, 1975). These psychoses have been classified as psychotic states with and without disturbances of consciousness (Bruens, 1975; Helmchen, 1975).

The first condition is a postparoxysmal state (ictal psychosis) characterised by confusion, disorientation, delusion, and hallucination. EEG recording may show generalised spikes, paroxysmal sharp waves, temporal theta and delta waves.

Psychotic states with a normal level of consciousness (interictal psychoses) are brief episodic attacks (depressive and dysphoric states) sometimes prolonged by chronic manic-depressive syndromes and paranoid or schizophrenia-like patterns. Interictal epileptic EEG activity may disappear during these episodes ("forced normalisation") (Landolt, 1958). In some patients these attacks alternate with epileptic seizures, the socalled "alternative psychoses" of Tellenbach (1965) and Janz (1969).

McDanal and Bolman (1975) and Wolf (1977) have drawn attention to the role of antiepileptic drugs in determining acute epileptic psychoses. They demonstrated that anticonvulsant plasma levels during psychotic attacks may be normal or low and that their aetiology is not necessary toxic,

Address for correspondence and reprint requests: Dr V. A. Sironi, Istituto di Neurochirugia dell'Universita, Pad. Beretta, Ospedale Policlinico, via F. Sforza 35, 20122 Milano, Italy.

Accepted 19 January 1979

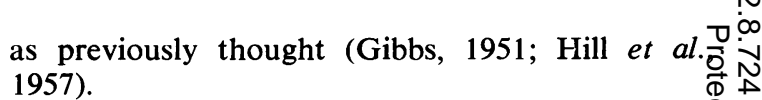

In this paper we present two patients suffering? from temporal lobe epilepsy who had psychotie attacks during withdrawal of anticonvulsant drugse during preoperative depth EEG study. Close coro relations between the clinical picture, depth EEQ activity, and plasma levels of clonazepam ar described.

\section{Method}

In patients considered for surgery, preoperative EEG studies with depth electrodes (depth EEG) and withdrawal of therapy are sometimes used for diagnostic purposes. In the two patients reported here, multilead stainless steel electrodes were implanted stereotactically according to Talairach's technique (Talairach et al., 1974; Cabrini et al., 1975; Marossero, 1975).

Four and five days respectively after implantation of the electrodes anticonvulsant medication was withdrawn. Evaluation of plasma levels of anticonvulsants permitted the maintenance of a plasma concentration which allowed the appearance of electrical seizures but not of severe clinical manifestations (Baruzzi et al., 1977; Marossero et al., 1977).

The determinations of anticonvulsant plasma levels were done by gas-liquid chromatography with the analytical procedures described by McGee (1970) for phenobarbitone, by Morselli et al. 
(1973) for carbamazepine, and by Gerna and Morselli (1976) for clonazepam. Drug concentrations were considered to be in therapeutic range when they fell within the following limits: phenobarbitone 15-40 $\mu \mathrm{g} / \mathrm{ml}$; carbamazepine 4-10 $\mu \mathrm{g} /$ $\mathrm{ml}$; clonazepam 15-70 $\mathrm{ng} / \mathrm{ml}$.

Psychiatric evaluation was performed during a series of interviews. The patients were given a battery of psychological tests including the Thematic Aperception and complete WechslerBellevue Intelligence Scale.

\section{Case reports}

\section{CASE 1}

This 28 year old man (PN) has been affected since the age of six years by weekly attacks of partial epileptic seizures with complex symptomatology, characterised by bodily sensation, impairment of consciousness, behavioural automatisms, and motor phenomena. From the age of 10 years occasional secondarily generalised seizures occurred. There is no history of birth trauma or other pathological events to which the seizures could be related.
Neurological examination showed no interictal deficits. Psychological and psychiatric studies showed moderate psychic impairment. At Wechsler-Bellevue Intelligence Scale examination he had a verbal IQ of 98 and performance IQ of 101. No previous psychiatric episode had occurred.

The patient was unresponsive to antiepileptic medication. In the year before admission he was treated with phenobarbitone $(150 \mathrm{mg} /$ day $)$ and clonazepam (3 mg/day). Anticonvulsant plasma level monitoring showed values of about 21.5$27.8 \mu \mathrm{g} / \mathrm{ml}$ for phenobarbitone and $14-17 \mathrm{ng} / \mathrm{ml}$ for clonazepam. Neuroradiological examination was normal.

On the basis of the clinical and EEG data, seven indwelling depth electrodes were placed stereotactically in the frontal, temporal, and parietal cortices, in the amygdala, Ammon's horn, and the fusiform gyrus on the right side, and in the mid-temporal cortex and Ammon's horn on the left side.

The clinical picture, depth EEG activity, and pharmacological correlations during the steady state condition, withdrawal and readministration of therapy are shown in Figs. 1 and 2.

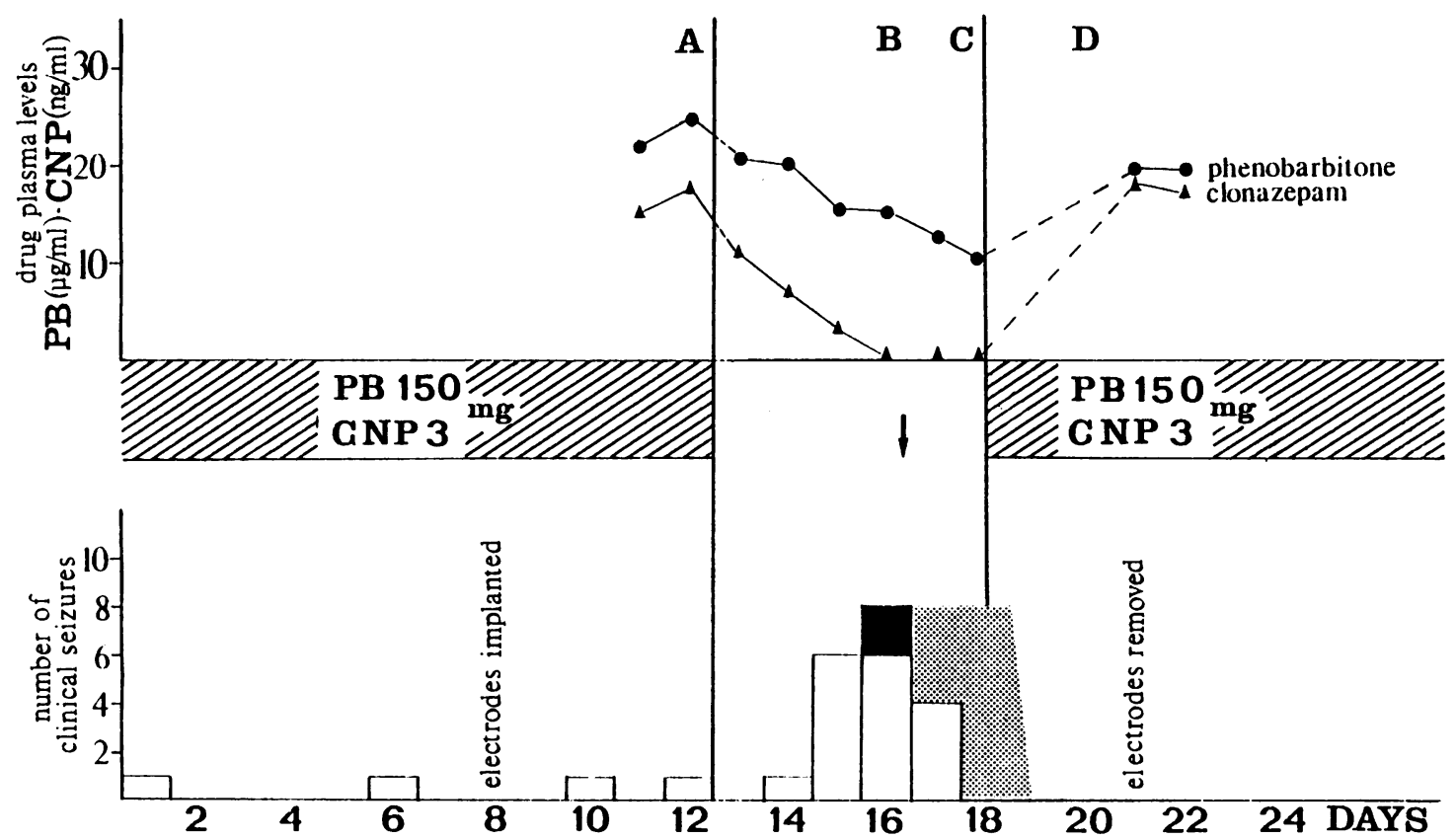

Fig. 1 Case 1. Correlations between clinical picture, aaily drug dosage, and anticonvulsant plasma levels during steady state condition, withdrawal, and readministration of therapy. $A, B$, and $C$ correspond to the days of registration of depth electrical activity reported in Fig. 2. In $D$ the electrical activity is similar to that in $A$. ( $\downarrow$ diazepam $5 \mathrm{mg} / \mathrm{iv})$. PB=phenobarbitone, CNP=clonazepam, $\square=$ psychomotor, $\square=$ secondarily generalised, $=$ acute psychotic attack. 

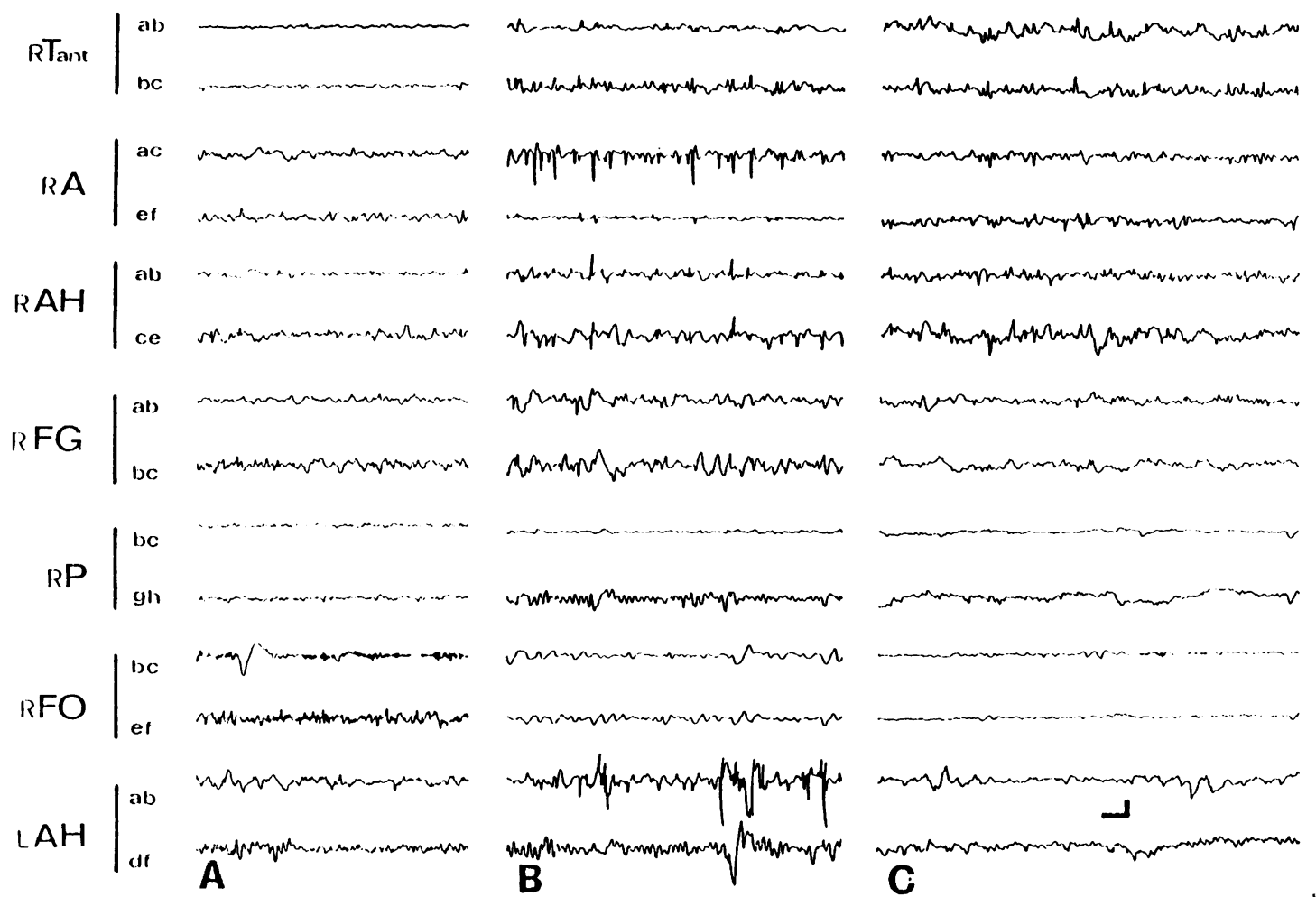

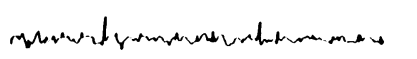

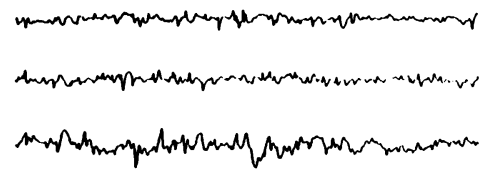

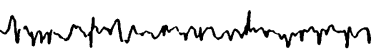

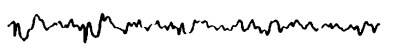

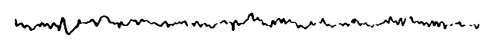

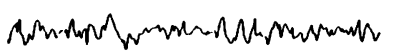
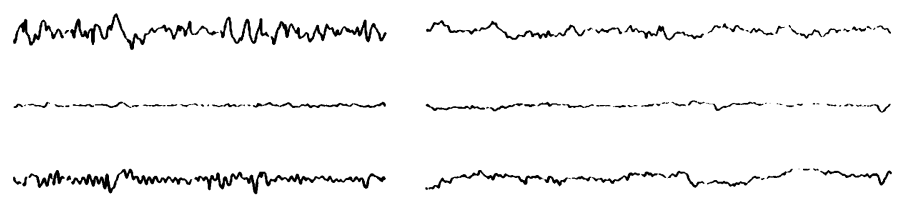

Fig. 2 Case 1. Interictal depth EEG recording. (A) Steady state: rare irritative activity in right rhinencephalic structures. $(B)$ Fourth day after withdrawal of treatment: asynchronous high voltage fast spikes in right amygdala and low voltage spikes in right temporal cortex and Ammon's horn. Independent high voltage spikes in left amygdala. (C) During acute psychotic attack: marked reduction of irritative activity with low voltage abnormalities in the right temporal cortex. Calibrations: $\mid 50 \mu V ;-1$ second. Placement of electrodes: right side: amygdala $(A), A$ mmon's horn $(A H)$, fusiform gyrus $(F G)$, parietal cortex $(P)$, anterior temporal cortex ( $T$ ant); left side: Ammon's horn $(A H), a, b$, and c are deep leads, $d, e, f, g$, and $h$ are superficial leads.

During the steady state condition the patient had few seizures and no mental changes. Anticonvulsant plasma levels were $21.8-238 \mu \mathrm{g} / \mathrm{ml}$ for phenobarbitone and $14-17 \mathrm{ng} / \mathrm{ml}$ for clonazepam. Interictal depth recording showed theta activity in the rhinencephalic structures and fast activity in the right fronto-orbital region. There was also occasional irritative activity in the right rhinencephalic structures (Fig. 2A).

During withdrawal of treatment the clinical picture was characterised by a progressive increase of partial seizures and the appearance of secondarily generalised seizure. Interictal depth EEG during the period of the progressive increase of the number of seizures showed asynchronous high voltage fast spikes in the right amygdala and low voltage spikes in the right temporal cortex and Ammon's horn. Independent high voltage spikes were also present in the left amygdala (Fig. 2B).
During the fifth day of therapy withdrawal (when plasma levels were $13.5 \mu \mathrm{g} / \mathrm{ml}$ for phenobarbitone and clonazepam was not detectable) the patient had an acute dysphoric state characterised by loss of verbal contact with unimpaired consciousness, childish excitement, outbursts of aggressiveness, hallucinations with religious preoccupations, and severe anxiety. Fine tremor of both hands was also present. During this state the psychomotor seizures disappeared, and depth EEG recording showed a marked reduction of irritative abnormalities. Only a rare low voltage irritative activity in the rhinencephalic structures and temporal cortices was present (Fig. 2C).

On the second day after the readministration of antiepileptic therapy, when plasma levels reached the values of about $14 \mu \mathrm{g} / \mathrm{ml}$ for phenobarbitone and $7 \mathrm{ng} / \mathrm{ml}$ for clonazepam, the dysphoric state disappeared. The patient had no seizures in the 
next six days, while depth EEG records showed the same electrical patterns as in the steady state recordings.

\section{CASE 2}

This 37 year old woman (CA) suffers from daily partial epileptic seizures with complex symptomatology, characterised by impairment of consciousness, autonomic symptoms, and automatisms with occasional secondarily generalised seizures.

Neurological examination was normal. Psychological study showed only moderate mental impairment. Wechsler-Bellevue Intelligence Scale examination showed a verbal IQ of 105 and a performance IQ of 94 . No previous psychiatric episode had occurred.

The patient was unresponsive to antiepileptic medication. In the 12 months before admission for surgery she was treated with phenobarbitone (200 mg/day), carbamazepine ( $800 \mathrm{mg} /$ day), and clonazepam (6 mg/day). Anticonvulsant plasma levels showed values of about $27-30 \mu \mathrm{g} / \mathrm{ml}$ for phenobarbitone, 4-6 $\mu \mathrm{g} / \mathrm{ml}$ for carbamazepine and $18-24 \mathrm{ng} / \mathrm{ml}$ for clonazepam.
The EEG study showed rhythmic low voltage spikes in the left temporal region and asynchronous irritative activity in the anteromedial right temporal region. Neuroradiological examination (including CAT scan) was normal.

On the basis of the clinical and EEG data, eight indwelling depth electrodes were placed stereotactically in the left parietal and temporal cortices, amygdala, and Ammon's horn, and in the right mid-temporal cortex and Ammon's horn.

The clinical picture, depth EEG recordings, and plasma level correlations are charted in Figs. 3 and 4.

During the steady state, the patient had few psychomotor seizures and no mental change. The values of anticonvulsant plasma levels were 25 $30 \mu \mathrm{g} / \mathrm{ml}$ for phenobarbitone, 4-6 $\mu \mathrm{g} / \mathrm{ml}$ for carbamazepine, and 17-20 $\mathrm{ng} / \mathrm{ml}$ for clonazepam. Depth recordings showed low voltage fast activity in the left frontal region, high voltage slow waves in the left temporal cortices, and high voltage spikes in the left amygdala and Ammon's horn. There were no irritative abnormalities recorded from the right rhinencephalic structures (Fig. 4A).

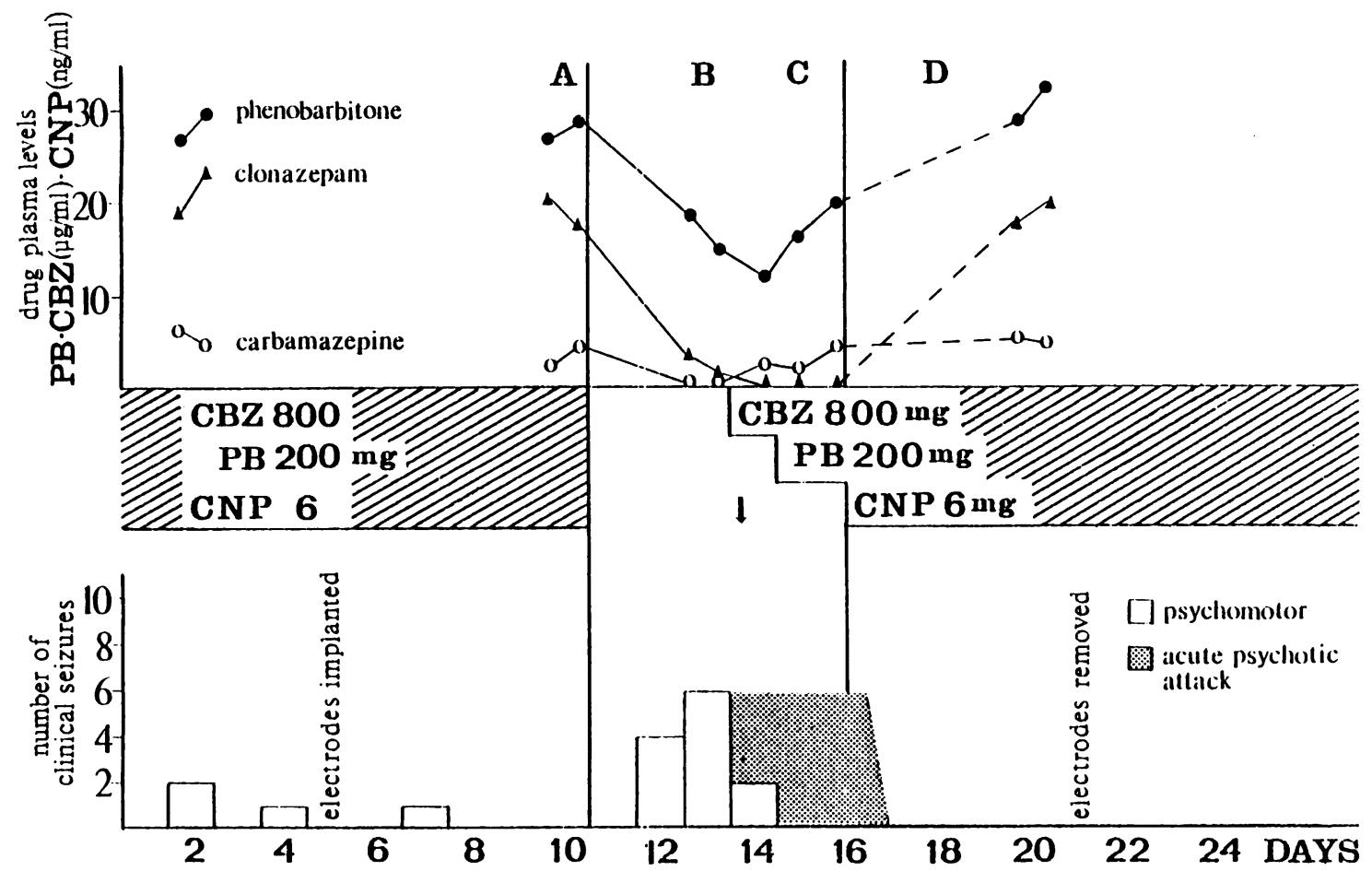

Fig. 3 Case 2. Correlations between clinical picture, daily drug dosage, and anticonvulsant plasma levels during steady state condition, withdrawal, and readministration of therapy. $A, B$, and $C$ correspond to the days of registration of depth electrical activity reported in Fig. 4. In $D$ the electrical activity is similar to that in $A$. ( $\downarrow$ diazepam $5 \mathrm{mg}$ iv). CBZ=carbamazepine, $C N P=$ clonazepam, $P B=$ phenobarbitone. 

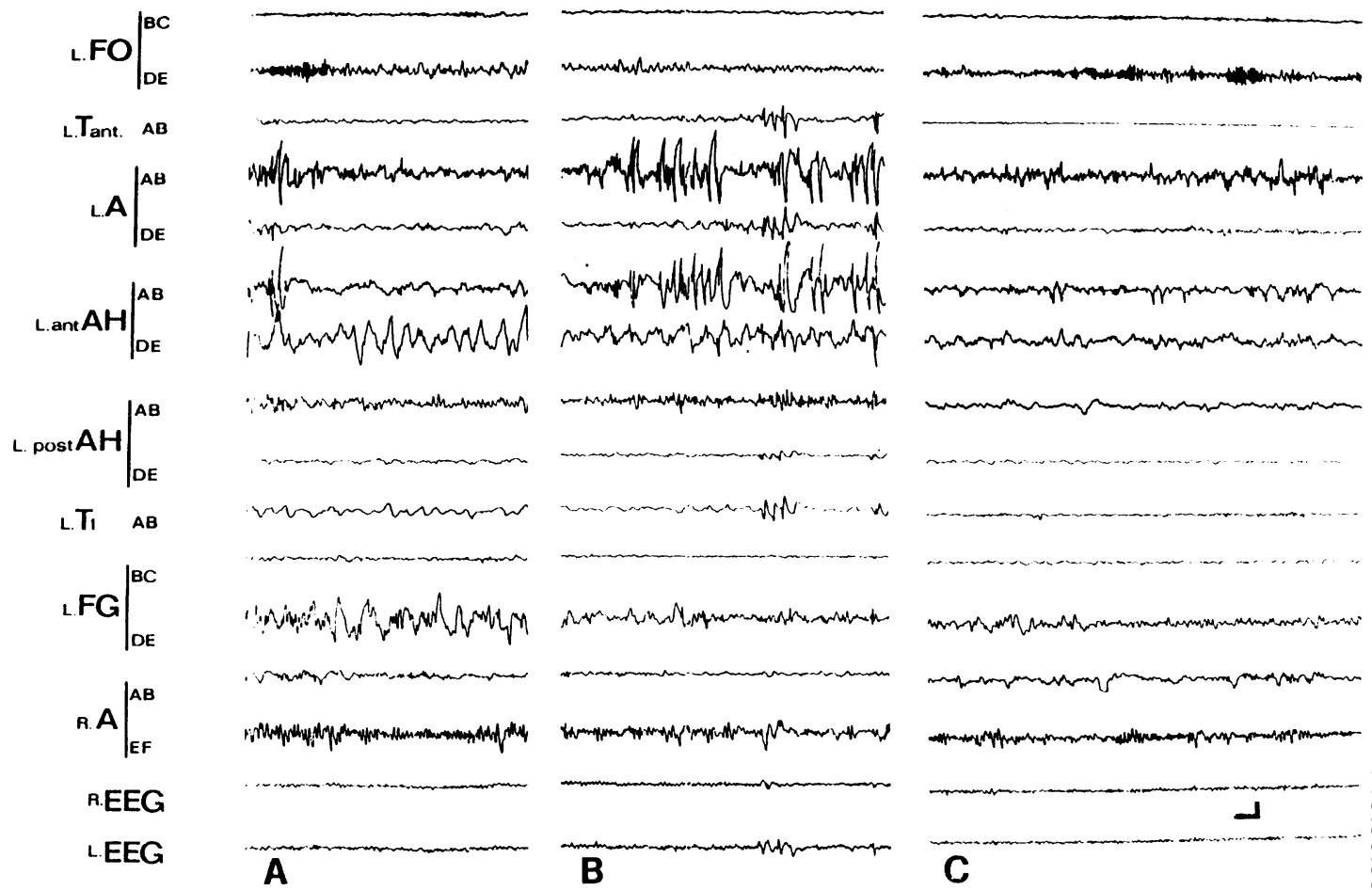

Fig. 4 Case 2. Interictal depth EEG recording. (A) Steady state: high voltage spikes in left amygdala and Ammon's horn. High voltage slow waves in left temporal cortex and low voltage fast activity in frontal region. (B) Third day after withdrawal of treatment: high voltage rhythmical spikes and polyspikes in left amygdala and Ammon's horn and in mid-temporal cortex. (C) During acute psychotic attack: disappearance of irritative activity in temporal cortex and rhinencephalic structures. Fast activity in right frontal region. Calibrations as in Fig. 2. Placement of electrodes: left side: amygdala (A), anterior and posterior Ammon's horn (ant/post $A H)$, fusiform gyrus (FG), fronto-orbital cortex (FO), temporal cortex (Tant/T1); right side: amygdala $(A) ; a, b$, and $c$ are deep leads, $d, e$, and $f$ are superficial leads.

Withdrawal of drugs provoked a progressive increase in the number of seizures starting from the second day, when the plasma levels were about $22 \mu \mathrm{g} / \mathrm{ml}$ for phenobarbitone, $1.5 \mu \mathrm{g} / \mathrm{ml}$ for carbamazepine, and $8 \mathrm{ng} / \mathrm{ml}$ for clonazepam. On the fourth day (plasma levels: phenobarbitone 12.5 $\mu \mathrm{g} / \mathrm{ml}$, carbamazepine $2 \mu \mathrm{g} / \mathrm{ml}$, clonazepam not detectable) the seizures disappeared and the patient had an acute dysphoric attack characterised by childish excitement with unimpaired consciousness, irritability, outbursts of aggressiveness, and hallucinations with religious preoccupations and sexual fantasies.

Depth EEG recording during the progressive increase of seizures after withdrawal of therapy showed low voltage spikes in the left anterior temporal cortex and high voltage fast spikes and polyspikes in the left amygdala and Ammon's horn (Fig. 4B). On the other hand, during the dysphoric state the recording showed an almost complete disappearance of the irritative abnormalities and the appearance of fast activity on the left fronto-orbital and right temporal cortices (Fig. 4C).

Symptomatic treatment with diazepam $(5 \mathrm{mg}$ intravenously) was started followed by readministration of carbamazepine $(600 \mathrm{mg} /$ day $)$ and phenobarbitone $(200 \mathrm{mg} /$ day $)$, without success in controlling the psychotic state. The psychotic symptomatology disappeared only after clonazepam was given $(6 \mathrm{mg} /$ day) and when plasma levels were about $22 \mu \mathrm{g} / \mathrm{ml}$ for phenobarbitone, $5 \mu \mathrm{g} / \mathrm{ml}$ for carbamazepine, and $6 \mathrm{ng} / \mathrm{ml}$ for clonazepam. At that time depth EEG records showed a picture similar to the steady state recording.

\section{Discussion}

After the acute withdrawal of chronic anticonvulsant therapy our two patients presented daily 
partial seizures during the first three days without mental changes, when anticonvulsant plasma levels ranged between 30 and $15 \mu \mathrm{g} / \mathrm{ml}$ for phenobarbitone, between $5 \mu \mathrm{g} / \mathrm{ml}$ and "nondetectable" levels for carbamazepine, and between 17 and 4 $\mathrm{ng} / \mathrm{ml}$ for clonazepam.

Depth EEG showed focal interictal and ictal irritative activity in the temporal cortices and rhinencephalic structures.

On the fourth and fifth day respectively the two patients became seizure-free and presented an acute dysphoric state characterised by childish excitement, severe anxiety, outbursts of aggressiveness, and hallucinations with religious preoccupations and sexual fantasies. Fine tremor of both hands was present in one of the two patients. Plasma levels of phenobarbitone were between 15 and $12 \mu \mathrm{g} / \mathrm{ml}$, carbamazepine levels were between 5 and $4 \mu \mathrm{g} / \mathrm{ml}$, while clonazepam was "not detectable."

Depth EEG recordings during these psychotic states were characterised by the almost complete disappearance of focal irritative activity and the appearance of fast activity in the frontal region with diffuse slow waves. These clinical and EEG pictures are different from those described as dreamy states (Lugaresi et al., 1971). On the other hand, the EEG pattern is very similar to the socalled "forced normalisation" described by Landolt (1958) during acute epileptic psychoses. The electrical abnormalities reported by Heath (1963), Glaser et al. (1963) and Bancaud et al. (1975) during psychotic attacks in epilepsy were not observed in our cases.

The psychiatric changes disappeared when therapy was readministered and plasma levels raised to the therapeutic range (phenobarbitone between 13-23 $\mu \mathrm{g} / \mathrm{ml}$, carbamazepine about $5 \mu \mathrm{g} /$ $\mathrm{ml}$, clonazepam about 5-7 $\mathrm{ng} / \mathrm{ml}$ ). Depth EEG findings became similar to the steady state recording characterised by focal irritative abnormalities.

There is some evidence of a possible pathogenetic role of acute withdrawal of clonazepam in the psychiatric and depth EEG changes reported:

1. The acute psychosis appeared only when the plasma level of clonazepam was not detectable, while levels of phenobarbitone and carbamazepine were near to the lower limit of the therapeutic range (phenobarbitone always over $12 \mu \mathrm{g} / \mathrm{ml}$, carbamazepine about $4-5 \mu \mathrm{g} / \mathrm{ml}$ ) during the psychotic attacks.

2. The psychiatric changes disappeared only when clonazepam was readministered and reached a plasma level of about $5-7 \mathrm{ng} / \mathrm{ml}$; this correlation was more evident in case 2 (Fig. 3).
3. These observations are similar to those reported by Sjo et al. (1975) in patients in whom the abrupt withdrawal of clonazepam produced pronounced dysphoria, irritability, restlessness, sleeplessness, and tremor of the hands. In those patients the clinical signs were also interpreted as withdrawal symptoms, and they disappeared almost immediately when small doses of clonazepam were readministered.

4. Low plasma levels of phenobarbitone, diphenylhydantoin, and carbamazepine after acute withdrawal during depth EEG recording have never been correlated with mental and psychotic abnormalities in our previous studies in patients suffering from partial complex epilepsy with rhinencephalic foci (Baruzzi et al., 1977; Marossero et al., 1977).

In conclusion, our observations suggest the possible role of acute withdrawal of clonazepam in determining acute psychotic attacks characterised by dysphoric manifestations, irritability, aggressiveness, anxiety, and hallucinations. These symptoms can be interpreted as a withdrawal syndrome. Depth EEG recordings confirmed the previous observations of "forced normalisation" during a psychotic attack in epileptic patients. These cases could be considered also as examples of the so-called "alternative psychoses" (Tellenbach, 1965; Janz, 1969).

\section{References}

Bancaud, J., Talairach, J., Bonis, A., Schaub, C., Szikla, G., Morel, P., and Bordas-Ferrer, M. (1975). La stéréo-électroéncefalograph:e dans l'epilepsie. Information neurophysiologiques apportées par l'investigations fonctionelle stéréotaxique. Masson: Paris.

Baruzzi, A., Cabrini, G. P., Gerna, M., Sironi, V. A., and Morselli, P. L. (1977). Anticonvulsant plasma level monitoring in epileptic patients undergoing stereo-EEG. In Anticonvulsant Drug Monitoring, pp. 317-334. Edited by C. Gardner-Thorpe, D. Janz, H. Meinardi, and C. E. Pippenger. Pitman Medical: Tunbridge Wells, Kent.

Bruens, J. H. (1975). Psychoses in epilepsy. In Handbook of Clinical Neurology, vol. 15, pp. 593-610. Edited by P. J. Vinken and G. W. Bruyn. NorthHolland: Amsterdam.

Cabrini, G. P., Ettorre, G., Marossero, F., Miserocchi, G., and Ravagnati, L. (1975). Surgery of epilepsy: some indication for SEEG. Journal of Neurosurgical Sciences, 19, 95-104.

Gerna, M., and Morselli, P. L. (1976). Simple and sensitive gas chromatographic method for the determination of clonazepam in human plasma. Journal of Chromatography, 116, 445-450.

Gibbs, F. (1951). Ictal and non-ictal psychiatric dis- 
orders in temporal lobe epilepsy. Journal of Mental and Nervous Diseases, 113, 522-527.

Glaser, G. H., Newman, R. J., and Schafer, R. (1963). Interictal psychosis in psychomotor-temporal lobe epilepsy: an EEG-psychological study. In EEG and Behavior, pp. 345-365. Edited by G. H. Glaser. Basic Books Inc: New York.

Heath, R. G. (1963). Closing remarks, with commentary on depth electroencephalography, in epilepsy and schizophrenia. In EEG and Behavior, pp. 377-393. Edited by G. H. Glaser. Basic Books Inc: New York.

Helmchen, H. (1975). Reversible psychic disorders in epileptic patients. In Epileptic Seizures-BehaviourPain, pp. 175-193. Edited by W. Birkmayer. Hans Huber: Stuttgart.

Hill, D., Pond, P. A., Mitchell, W., and Falconer, M. A. (1957). Personality changes following temporal lobectomy for epilepsy. Journal of Mental Science, 103, 18-27.

Janz, D. (1969). Die Epilepsien. Georg Thieme: Stuttgart.

Landolt, H. (1958). Serial EEG investigations during psychotic episodes in epileptic patients and during schizophrenic attacks. In Lectures on Epilepsy, pp. 91-133. Edited by A. M. Lorenz de Haas. Elsevier: Amsterdam.

Lugaresi, E., Pazzaglia, P., and Tassinari, C. A. (1971). Differentiation of "absence status" and "temporal lobe status". Epilepsia, 12, 77-87.

McDanal, C. E., and Bolman, W. M. (1975). Delayed idiosyncratic psychosis with diphenylhydantoin. Journal of the American Medical Association, 231, 1063-1064.

McGee, J. (1970). Rapid determination of diphenylhydantoin in blood plasma by gas-liquid chromatography. Analytical Chemistry, 42, 421-422.
Marossero, F. (1975). Surgery of epilepsy. Diagnostic importance of SEEG. Introduction. Journal of Neurosurgical Sciences, 19, 84-88.

Marossero, F., Cabrini, G. P., Sironi, V. A., and Baruzzi, A. (1977). Correlations of anticonvulsant plasma levels with depth EEG recordings in epileptic patients (abstract). Electroencephalography and Clinical Neurophysiology, 43, 527.

Morselfi, P. L., Biandrante, P., Frigerio, A., Gerna, M. and Tognoni, G. (1973). Gas chromatographic determination of carbamazepine and carbamazepine10-11-epoxide in human body fluids. In Methods of Analysis of Antiepileptic Drugs, pp. 169-175. Edited by J. W. A. Meyer, H. Meinardi, C. GardnerThorpe, and C. Van der Kleijn. Excerpta Medica: Amsterdam.

Pond, D. A. (1975). Epilepsy and personality disorders. In Handbook of Clinical Neurology, vol. 15, pp. 576592. Edited by P. J. Vinken and G. W. Bruyn. North-Holland: Amsterdam.

Sjo, O., Hvidberg, E. F., Naestoft, J., and Lund, M. (1975). Pharmacokinetics and side-effects of clonazepam and its 7-amino-metabolite in man. European Journal of Clinical Pharmacology, 8, 249-254.

Talairach, J., Bancaud, J., Szikla, G., Bonis, A., Geier, S., and Vendrenne, C. (1974). Approuche nouvelle de la neurochirurgie de l'épilepsie. Method ologie stéréotaxique et resultats thérapeutiques Neurochirurgie, 20, supplement 1, 1-240.

Tellenbach, H. (1965). Epilepsie als Anfallsleiden und als Psychose. Uber alterative Psychoses paranoideo Prägung bei "forcierter Normalisierung" (Landolt) des Elektroencephalogramms Epileptischer. Nero venarzt, 36, 190-197.

Wolf, P. (1977). The role of antiepileptic drugs in epileptic psychoses. In Post-traumatic Epilepsy and Pharmacological Prophylaxis, pp. 248-255. Edited by J. Majkowski. Printing Office Tamka: Varsavia. 